\title{
Diferentes Densidades de Estocagem na Produção de Alevinos de Trairão (Hoplias cf. lacerdae)
}

\section{Ana Lúcia Salaro1, Ronald Kennedy Luz², Gláucio Cristiano Cabral de Barros Nogueira ${ }^{3}$, Alex Reis ${ }^{4}$, Róberson Sakabe ${ }^{5}$, Daniel Moreira Lambertucci ${ }^{6}$}

\begin{abstract}
RESUMO - Alevinos de trairão (Hoplias cf. lacerdae), com peso e comprimento total médios de 12,52 g e 10,5 cm, respectivamente, previamente condicionados ao aceite de dietas artificiais, foram distribuídos em seis tanques de alvenaria $\left(5 \mathrm{~m}^{2}\right)$ nas densidades de: $1 \mathrm{e}$ 4 alevinos $/ \mathrm{m}^{2}$. Os peixes dos diferentes tratamentos foram alimentados ad libitum nos horários de 8 e $14 \mathrm{~h}$ com ração comercial extrusada contendo $42 \%$ de proteína bruta. A cada trinta dias realizou-se a troca do volume total de água de todos os tanques. Ao final do experimento (120 dias) foi avaliado o desempenho produtivo dos peixes, por meio da taxa de sobrevivência, conversão alimentar, ganhos em comprimento e em peso diário. Foram observadas taxas médias de sobrevivência de 86,7 e $96,7 \%$ para as densidades de 1 e 4 peixes $/ \mathrm{m}^{2}$, respectivamente. A conversão alimentar foi de 1,6 e 1,2; o ganho em peso diário e em comprimento de 0,70 e $0,38 \mathrm{~g}$ e 8,01 e 7,27 cm, respectivamente. Estes valores não diferiram entre si. Com os resultados obtidos pode-se concluir que as densidades de estocagem de 1 e 4 peixes $/ \mathrm{m}^{2}$ podem ser utilizadas no cultivo de alevinos de trairão sem que haja comprometimento no seu desempenho produtivo.
\end{abstract}

Palavras-chave: densidade de estocagem, Hoplias cf. lacerdae, trairão

\section{Effect of Two Stocking Rates on the Trairão (Hoplias cf. lacerdae) Fingerlings Performance}

\begin{abstract}
Trairão (Hoplias cf. lacerdae) fingerlings, averaging $12.52 \mathrm{~g}$ and $10.5 \mathrm{~cm}$, respectively, previously trained to accept artificial feed, were stocked in six tanks $\left(5 \mathrm{~m}^{2}\right)$, under two stocking rates: 1 and 4 fingerling $/ \mathrm{m}^{2}$, constituting the treatments $\mathrm{t} 1$ and $\mathrm{t} 2$, respectively. The fishes of the different treatments were ad libitum fed an extruded commercial diet containing $42 \%$ crude protein, at 8 a.m. and 2 p.m. at each 30 days, the water volume of all tanks was $100 \%$ replaced. at the end of the experiment, 120 days, the fishes productive performance was evaluated by means of survival rate, feed:gain ratio and daily length and weight gains. average survival rates of 86.7 and $96.7 \%$ were observed for the stocking rates of 1 and $4 \mathrm{fish} / \mathrm{m}^{2}$, respectively. feed:gain ratio of 1.6 and 1.2 and daily length and weight gains of .70 and $.38 \mathrm{~g}$ and 8.01 and $7.27 \mathrm{~cm}$, respectively, were obtained for both densities. these values did not differ from each other. it was concluded that it is viable to produce the trairao fingerlings, under the evaluated stocking rates, without reducing performance.
\end{abstract}

Key Words: Hoplias cf. lacerdae, stocking rates, "trairão"

\section{Introdução}

Nos últimos anos, a piscicultura brasileira vem apresentando avanços significativos em sua produção. Cresce também a demanda por estudos relacionados às diferentes espécies com potencial zootécnico que atendam as exigências do mercado consumidor em qualidade de carne e características relacionadas à pesca esportiva.

O trairão (Hoplias cf. lacerdae) tem sua criação em cativeiro ainda limitada devido a problemas relacionados ao hábito alimentar carnívoro, o qual acarreta altos índices de mortalidade já nos primeiros dias de vida (Luz et al., 2000). Estudos com condicionamento alimentar de peixes carnívoros com dietas artificiais vem diminuindo os índices de canibalismo existentes nessas espécies (Salaro et al., 2000; Sakabe et al., 2000; e Luz et al., 2001). Associado ao canibalismo, a densidade de estocagem é outro fator importante a ser considerado, por interferir no crescimento, na eficiência alimentar e sobretudo na sobrevivência (Iwamoto, 1986). A densidade de estocagem também interfere no comportamento dos peixes (Stickney, 1994).

Segundo Jobling (1994), baixas densidades podem levar ao subaproveitamento do espaço, enquanto que altas densidades provocam contaminação da

\footnotetext{
${ }^{1}$ Bióloga, Profa Depto Biologia Animal, UFV, MG/Brasil. E.mail: salaro@mail.ufv.br

2 Eng. Agrônomo, Doutorando em Aqüicultura/CAUNESP, Bolsista/CAPES. E.mail: luzrk@yahoo.com

${ }^{3}$ Estudante de Zootecnia da UFV, Bolsista PIBIC/CNPq.

4 Zootecnista UFV. E.mail: reis-s-p@yahoo.com

${ }^{5}$ Aluno do curso de Medicina Veterinária da UFV.

${ }^{6}$ Aluno do curso de Zootecnia da UFV.
} 
água por excesso de excreção nitrogenada, principalmente quando se trata de espécies carnívoras. A densidade elevada pode também ser considerada um potencial estressor dos peixes e, conseqüentemente, reduzir a capacidade produtiva dos mesmos. Segundo Lefrançois (2001), o estresse provocado é prejudicial ao crescimento provocando alterações na agressividade e perseguição social, gerando maior exigência metabólica e alteração no comportamento alimentar dos peixes.

Com base no exposto acima, o estudo de densidades de estocagem no cultivo de alevinos de trairão faz-se necessário para se avaliarem estratégias de manejo para esta espécie.

\section{Material e Métodos}

O presente experimento foi realizado na Estação de Hidrobiologia e Piscicultura do Departamento de Biologia Animal - Universidade Federal de Viçosa UFV - Viçosa- MG, durante o período de agosto a novembro de 2001, com duração de 120 dias.

Lotes homogêneos de alevinos de trairão (Hoplias cf. lacerdae) com o peso médio de 12,52 g e comprimento médio total de $10,5 \mathrm{~cm}$, previamente treinados a receber dietas artificiais, foram distribuídos em seis tanques de alvenaria de $5 \mathrm{~m}^{2}$ cada, em sistema de baixa renovação de água. Os peixes foram submetidos as densidades de 1 e 4 alevinos $/ \mathrm{m}^{2}$, constituindo os tratamentos $\mathrm{T} 1 \mathrm{e} \mathrm{T} 2$, respectivamente.

Os peixes foram alimentados diariamente nos horários de 8 e 14 h com ração comercial extrusada contendo $42 \%$ de proteína bruta (Tabela 1) ad libitum. Durante o período de alimentação, os alevinos foram observados por trinta minutos para detectar possíveis sobras de alimento. A cada trinta dias, realizouse a troca do volume total de água de todos os tanques. A temperatura da água foi aferida diariamente no período da manhã e da tarde, antes do fornecimento da ração.

Ao final do experimento, 120 dias, foi efetuada a despesca total dos peixes de todos os tratamentos e realizada a biometria dos mesmos. Com os dados de peso e comprimento total, foram calculados os seguintes índices zootécnicos: ganho em peso diário (Gpd) e em comprimento $(\mathrm{Gc})$ pelas fórmulas: ganho em peso diário $(\mathrm{g} / \mathrm{dia})=$ peso final - peso inicial $/$ dias de cultivo (dias) e ganho em comprimento $(\mathrm{cm})=$ comprimento final - comprimento inicial.

Por contagem direta dos alevinos, determinou-se a taxa de sobrevivência dos peixes de cada tratamento. A conversão alimentar foi obtida pela seguinte fórmula: CA = consumo de ração/biomassa final - biomassa inicial.

Os dados de sobrevivência, conversão alimentar, ganhos em peso diário e em comprimento, dos diferentes tratamentos durante todo o período experimental foram submetidos ao teste $t$ de Student.

\section{Resultados e Discussão}

Os valores médios de temperatura da água registrados nos períodos da manhã e tarde, mantiveramse entre 22,3 e $26,1^{\circ} \mathrm{Ce} 25,7$ e $29,6^{\circ} \mathrm{C}$, respectivamente. Estes valores encontram-se dentro da faixa térmica de conforto para a espécie. Segundo Andrade et al. (1998), o trairão é uma espécie carnívora, nativa das regiões amazônica e centro-oeste, sendo a faixa de temperatura de 24 a $32^{\circ} \mathrm{C}$ ideal para o seu bom desenvolvimento.

Constam na Tabela 2 os dados de taxa de sobrevivência, ganhos em peso diário e em comprimento e a conversão alimentar de alevinos de trairão (Hoplias cf. lacerdae) estocados nas densidades de 1 e 4 peixes $/ \mathrm{m}^{2}$.

Com relação à taxa de sobrevivência dos peixes foram observados valores de 86,7 e $96,7 \%$ para as densidades de 1 e 4 peixes $/ \mathrm{m}^{2}$, respectivamente (Tabela 2). Sendo o hábito alimentar carnívoro dessa espécie, tais taxas podem ser consideradas elevadas. Uma hipótese importante seria o fato da utilização de lotes homogêneos de peixes e o oferecimento ad libitum da ração aos animais.

Durante o manejo alimentar, observou-se que, na maior densidade de estocagem, os alevinos formavam cardumes na meia água para a captura da ração, não sendo registrado agressividade entre os peixes. Resul-

Tabela 1 - Composição químico-bromatológica da dieta Table 1 - Chemical-bromatological composition of diets

\begin{tabular}{lc}
\hline $\begin{array}{l}\text { Nutrientes } \\
\text { Nutrients }\end{array}$ & $\begin{array}{c}\text { Composição (\%) } \\
\text { Composition }\end{array}$ \\
\hline $\begin{array}{l}\text { Proteína bruta } \\
\text { Crude protein }\end{array}$ & 42,0 \\
Extrato etéreo & \\
Ether extract & 7,0 \\
Fibra & \\
Fiber & 4,0 \\
Minerais & 15,0 \\
Mirerals & \\
Cálcio & 3,0 \\
Calcium & \\
Fósforo & \\
Phosphorus & \\
\hline
\end{tabular}


tados semelhantes foram encontrados por Paiva \& Baldisseroto (2000) para o jundiá (Rhamdia quelen), onde verificaram que maiores densidades de estocagem favorecem a formação de grupos na captura de alimentos. O aumento da densidade de estocagem contribuiu para o não territorialismo entre os peixes e, conseqüentemente, para a diminuição do canibalismo.

Observou-se também na menor densidade estudada maior heterogeneidade de tamanho entre os peixes, o que, de acordo com Luz et al. (2000), é um dos fatores que levam ao canibalismo. A heterogeneidade encontrada neste tratamento poderia ter contribuído para a menor sobrevivência dos peixes. Segundo esse mesmo autor, a homogeneidade do lote é fundamental para o sucesso da criação dessa espécie.

Segundo Katavic et al. (1989), altas densidades de estocagem juntamente com alimentação inadequada ou insuficiente seriam os principais fatores que levariam ao canibalismo entre os peixes cultivados. De acordo com Pienaar (1990), o canibalismo pode ser controlado por simples alteração na disponibilidade de alimento.

Taxa de sobrevivência semelhante à encontrada nesse trabalho foi observada por Honczaryk \& Maeda (1998), para alevinos de pirarucu (Arapaima gigas) e por Sakabe et al. (2000), para alevinos de trairão (Hoplias cf. lacerdae), quando cultivados no período de inverno.

Os dados de conversão alimentar; ganhos em peso diário e em comprimento foram de: 1,6 e 1,2; 0,70 e 0,38 g e 8,0 e $7,3 \mathrm{~cm}$, respectivamente, para as densidades de 1 e 4 peixes $/ \mathrm{m}^{2}$ (Tabela 2). Embora não tenham sido constatadas diferenças significativas $(\mathrm{P}<0,05)$, entre os tratamentos, observou-se tendência de maiores ganhos em peso diário e em comprimento para os peixes do tratamento 1 .

Campos (1998) observou valores semelhantes de conversão alimentar $(1,2$ a 1,4:1) para surubins (Pseudoplatystoma corruscans e P. fasciatum) cultivados em "raceways". Já, Scorvo-Filho et al. (1998), trabalhando com o dourado (Salminus maxillosus) na densidade de 1 peixe $/ \mathrm{m}^{2}$, encontraram valores de conversão alimentar de 3,5 e 10,2:1. Alevinos de pirarucu (Arapaima gigas) quando alimentados com ensilado biológico apresentaram conversão alimentar de 5,9:1 (Honczaryk \& Maeda, 1998).

Sakabe et al. (2000), estudando diferentes densidades de estocagens para alevinos de trairão (Hoplias cf. lacerdae) cultivados durante o período de inverno, obtiveram valores de conversão alimentar de 1,8;1,9 e 5,4 para as densidades de 1,2 e 4 peixes $/ \mathrm{m}^{2}$. Salaro et al. (2000), trabalhando com a mesma espécie em laboratório, porém na densidade de estocagem de 0,7 alevino/L, obtiveram valores de conversão alimentar de 2,0:1 para os peixes que receberam $5 \%$ do peso de ração/dia e de 3,5:1 para aqueles que foram arraçoados com $8 \%$.

Segundo Hecht \& Appelbaum (1988) e Van Damme et al. (1989), a maior heterogeneidade de tamanho observada nos alevinos estocados na densidade de 1 peixe $/ \mathrm{m}^{2}$ pode ter alterado o comportamento dos peixes, principalmente no que se refere ao canibalismo. Luz et al. (2000) observaram 100\% de canibalismo dos peixes menores quando alevinos de trairão foram estocados em classes de tamanhos heterogêneos em um mesmo aquário. Esse comportamento diminuiu à medida que se uniformizavam os valores de comprimento dos alevinos. Fato semelhante também foi observado por Folkvord (1991).

Diversos autores têm relatado a influência da densidade de estocagem sobre o crescimento e o canibalismo entre os peixes. Altas densidades mostraram-se favoráveis tanto ao crescimento de juvenis do bagre africano (Clarias gariepinus) (Hecht \& Uys, 1997) como para o jundiá, (Rhamdia quelen) (Piaia \& Baldisserotto, 2000), entretanto, reduziram o crescimento de alevinos do bagre do canal (Ictalurus punctatus) em tanques de terra (Esquivel et al., 1997).

Gomes (2000), estudando larvas de matrinxã (Brycon cephalus), verificou que o comprimento e peso foram significativamente reduzidos com o aumento da densidade de estocagem. Entretanto, esse mesmo autor não observou correlação entre a sobre-

Tabela 2 - Valores de sobrevivência, ganho de peso diário, ganho em comprimento total e conversão alimentar de alevinos de trairão cultivados em diferentes densidades

Table 2 - Values survival, daily weight gain, length gain and feed:gain ratio

\begin{tabular}{llc}
\hline & \multicolumn{2}{c}{$\begin{array}{c}\text { Densidade } \\
\text { Density }\end{array}$} \\
\cline { 2 - 3 } & \multicolumn{1}{c}{$1 \mathrm{px} / \mathrm{m}^{2}$} & $4 \mathrm{px} / \mathrm{m}^{2}$ \\
\hline $\begin{array}{l}\text { Sobrevivência \% } \\
\text { Survival \% }\end{array}$ & $86,7 \pm 11,5$ & $96,7 \pm 2,8$ \\
$\begin{array}{l}\text { Ganho em peso diário }(\mathrm{g}) \\
\text { Daily weight gain }\end{array}$ & $0,70 \pm 0,45$ & $0,38 \pm 0,07$ \\
$\begin{array}{l}\text { Ganho em comprimento }(\mathrm{cm}) \\
\text { Length gain }\end{array}$ & $8,0 \pm 2,8$ & $7,3 \pm 0,5$ \\
$\begin{array}{l}\text { Conversão alimentar } \\
\text { Feed:gain ratio }\end{array}$ & $1,6 \pm 0,46$ & $1,2 \pm 0,18$ \\
\hline
\end{tabular}

Letras diferentes, na linha, indicam diferença significativa no teste " $t$ " $(P<0,05)$

Different letters in the line show significant $(P<.05)$ difference by "t" test.

R. Bras. Zootec., v.32, n.5, p.1033-1036, 2003 
vivência e densidade de estocagem.

Fosse et al. (1996), avaliando três diferentes densidades de estocagem $\left(1,2\right.$ e 3 peixes $\left./ \mathrm{m}^{2}\right)$ para o pintado (Pseudoplatystoma corruscans) alimentados com dietas à base de vísceras de frango, observaram melhores desempenhos produtivos para os animais estocados a densidade de 1 peixe $/ \mathrm{m}^{2}$. Del Carratore (1998) concluiu que a densidade mais adequada para juvenis desta mesma espécie em tanques-rede, estaria em torno de 15 peixes $/ \mathrm{m}^{3}$.

Com base nos resultados obtidos, pode-se inferir que alevinos de trairão podem ser criados nas densidades de 1 e 4 peixes $/ \mathrm{m}^{2}$ sem terem seu desempenho produtivo afetado, sendo que a densidade de 4 peixes $/ \mathrm{m}^{2}$ apresentou melhores índices de sobrevivência, podendo ser esta a mais indicada para esta espécie.

\section{Conclusões}

Alevinos de trairão (Hoplias cf. lacerdae) podem ser cultivados nas densidades de 1 e 4 peixes $/ \mathrm{m}^{2}$, sem que haja comprometimento no seu desempenho produtivo.

A densidade de 4 peixes $/ \mathrm{m}^{2}$ proporcionou o maior índice de sobrevivência dos alevinos de trairão.

\section{Literatura Citada}

ANDRADE, D.R.; VIDAL, M.V.J.; SHIMODA, E. Criação do trairão Hoplias lacerdae. Campos dos Goytacazes: Universidade Estadual do Norte Fluminense, 1998. 23p. (Boletim Técnico, 3)

CAMPOS, J.L. Produção Intensiva de Peixes de Couro no Brasil. In: SIMPÓSIO SOBRE MANEJO E NUTRIÇÃO DE PEIXES, 2., 1998, Piracicaba. Anais... São Paulo: 1998. p. 61-72.

DEL CARRATORE, C.R.; MACHADO, J.H.; VILEM, R. et al. Desempenho produtivo de juvenis de Pintado (Pseudoplatystoma corruscans), estocados em tanques-rede em diferentes densidades de estocagem. In: SIMPÓSIO BRASILEIRO DE AQUICULTURA, 10., 1998, Recife. Resumos... Recife: 1998. p.262.

ESQUIVEL, B.M.; ESQUIVEL, J.R.; ZANIBONI FILHO, E. Effects of stocking density on growth of channel catfish, Ictalurus punctatus, fingerlings in Southern Brazil. Journal of Applied Aquaculture, v. 7, n.3, p.1-6, 1997.

FOSSE, P.J.; MENDONÇA, J.O.J.; SENHORINE, J.A. Influência da densidade de estocagem e utilização de vísceras de frango no crescimento do pintado (Pseudoplatystoma corruscans) (AGASSIZ, 1829). In: SIMPÓSIO BRASILEIRO DE AQUICULTURA, 9., 1996, Sete Lagoas. Resumos... Sete Lagoas: 1996. p.468.

FOLKVORD, A. Growth, survival and cannibalism of cod juveniles (Gadus morhua): effects of feed type, starvation and fish size. Aquaculture, v.97. p.41-59, 1991.

GOMES, L.C.; BALDISSEROTTO, B.; SENHORINI, J.A. Effect of stocking density on water quality, survival, and growth of larvae of the matrinxã, Brycon cephalus (Characidae), in ponds. Aquaculture, v.183, p.73-81, 2000.
HECHT, T.; APPELBAUM. S. Observations on intraspecific aggression and coeval sibling cannibalism by larva and juvenile Clarias gariepinus (Clariidae: Pisces) under controlled conditions. Journal of Zoology, v.214, p.21-44, 1988.

HECTH, T.; UYS, W. Effect of density on the feeding and aggressive behaviour in juvenile African catfish, Clarias gariepinus. South African Journal of Science, v.93, p.537-541, 1997.

HONCZARYK, A.; MAEDA, E.L.S. Observações sobre o crescimento do "pirarucu", Arapaima gigas (CUVIER, 1829) utilizando uma dieta à base do ensilado biológico de pescado. In: SIMPÓSIO BRASILEIRO DE AQUICULTURA, 10., 1998, Recife. Resumos... Recife: 1998. p.3.

IWAMOTO, R.N.; MYERS, J.M.; HERSHBERGER, W.K. Genotype-environmental interactions for growth of rainow trout, Salmo gairdneri. Aquaculture, v.57, n.14, p.153-51, 1986.

JOBLING, M. Fish bioenergetics. London: Chapman \& Hall, 1994. 294p.

KATAVIC, I.; JUDGUJAKOVIC, J.; GLAMUZINA, B. Cannibalism as a factor affecting the survival of intensively cultured sea bass (Dicentrarchus labrax) fingerlings. Aquaculture, v.77, p.135-143, 1989.

LEFRANÇOIS, C.; CLAIREAUXA, G.; MERCIERA, C. et al. Effect of density on the routine metabolic expenditure of farmed rainbow trout (Oncorhynchus mykiss). Aquaculture, v.195, p.269-277, 2001

LUZ, R.K.; SALARO, A.L.; SOUTO, E.F. et al. Avaliação de canibalismo e comportamento territorial de alevinos de trairão (Hoplias lacerdae). Acta Scientiarum, v.22, n.2, p.465-469, 2000.

LUZ, R.K.; SALARO, A.L.; SOUTO, E.F. et al. Desenvolvimento de alevinos de trairão alimentados com dietas artificiais em tanques de cultivo. Revista Brasileira de Zootecnia, v.30, n.4, p.1159-1163, 2001.

PIAIA, R.; BALDISSEROTTO, B. Densidade de estocagem e crescimento de alevinos de jundiá Rhamdia quelen (QUOY \& GAIMARD, 1824) fingerlings. Ciência Rural, v.30, n.3, p.509-513, 2000 .

PIENAAR, A.G. A study of coeval sibling cannibalism in larval and juvenile fishes and its control under culture conditions. Grahamstown: (Magisters thesis) - Rhodes University, Grahamstown. South Africa, 1990.

SAKABE, R.; SALARO, A.L.; LUZ, R.K. et al. Densidade de estocagem de alevinos de trairão (Hoplias lacerdae), cultivados durante o período de inverno. In: SIMPÓSIO BRASILEIRO DE AQUiCUltura, 11., 2000, Florianópolis. Anais... Florianópolis: 2000. (CD ROM)

SALARO, A.L.; LUZ, R.K.; SOUTO, E.F. Sobrevivência e conversão alimentar de alevinos de trairão (Hoplias lacerdae), alimentados com dietas artificiais. In: SIMPÓSIO BRASILEIRO DE AQUICULTURA, 11., 2000, Florianópolis. Resumos... Florianópolis: 2000. (CD ROM)

SCORVO-FILHO, J.D.; AYROZA, L.M.S.; ROMAGOSA,E. Observações sobre a manutenção do "dourado" Salminus maxillosus, em cativeiro na região do Vale do Ribeira, SP. In: SIMPÓSIO BRASILEIRO DE AQUICULTURA, 10., 1998, Recife. Resumos... Recife: 1998. p.268.

STICKNEY, R.R. Principles of aquaculture. New York: John Wiley \& Sons, 1994. 502p.

Van DAMME, P.; APPELBAUM, S.; HECHT, T. Sibling cannibalism in koi carp, Cyprinus carpio L., larvae and juveniles reared under controlled conditions. Journal of Fish Biology, v.34, p.855-863, 1989.

Recebido em: 10/09/02 Aceito em: 08/01/03

R. Bras. Zootec., v.32, n.5, p.1033-1036, 2003 